\title{
Prevalence and Associated Behavioral Factors of Depression among Private Medical Students in Bangladesh
}

Dr. Arifa Sultana*

Medical Officer, Life Diagnostic Centre, Nayapaltan, Dhaka, Bangladesh

DOI: $10.36347 /$ sjams.2021.v09i01.010

| Received: 16.12.2020 | Accepted: 26.12.2020 | Published: 09.01.2021

*Corresponding author: Dr. Arifa Sultana

Abstract

Original Research Article

Objective: To identify the prevalence and factors associated with depression among medical students. Method: This is an analytical cross-sectional study that was used to measure the prevalence of depression related factors among students in medical colleges in Dhaka. Study population consisted of medical students in medical college institutions at Dhaka, Bangladesh. Dhaka Medical College, Mugda Medical College, Delta Medical College and Holy Cross Medical College and Hospital were selected as the study sites. The sites were selected purposely depending on the fulfillment of the criteria that all these are located in Dhaka, provide medical education and training at different levels and are accessible to the researchers. Study period was from August 2019 to December 2019. Questionnaire was coded before entering the data to the computer by the researcher. Results: The response rate was $86.11 \%$ and subjects comprised $162(52.26 \%)$ male respondents and $148(47.74 \%)$ female respondents with a mean age of 21.4 years. While $33.87 \%$ students $(n=105)$ are $1^{\text {St }}$ and $2^{\text {"d }}$ year students, $39.35 \%$ students $(n=122)$ students study in $3^{\text {rd }}$ and $4^{\text {th }}$ year, leaving $26.77 \%(n=83)$ students in the final year of their study. Among the respondents, 34.84\% ( $n=108)$ students reside in hostels and $65.16 \%$ students $(n=202)$ reside in their own house. The odds of female students developing depression is found to be 2.12(1/0.4741) times higher than their male counterparts when the other factors are adjusted (AOR 0.4741, $\mathrm{p}$ value 0.0162). There is also a significant association between sleep and depression ( $\mathrm{p}$ value 0.0460 ) which suggests that the odds of those sleeping $<8$ hours per day having depression is $1.82(110.5491)$ times higher than those sleeping for more than 8 hours per day. Other factors did not show any significant association after adjustment. Conclusion: The prevalence of depression is quite high among medical students at undergraduate level in Bangladesh. Different factors like sex, academic year, age, residence etc. have been proven to be independently associated with these psychological conditions at varying degree.

Keywords: Depression, Prevalence, Medical Students.

Copyright $\odot 2021$ The Author(s): This is an open-access article distributed under the terms of the Creative Commons Attribution 4.0 International License (CC BY-NC 4.0) which permits unrestricted use, distribution, and reproduction in any medium for non-commercial use provided the original author and source are credited.

\section{INTRODUCTION}

Mental health is an issue that has been increasingly gaining more and more significance in the discourse of health of the $21^{51}$ century humanity [1]. Depression. Anxiety and stress have emerged as major contributors to the global burden of diseases, with WHO reporting 300 million people suffering from depression [2]. Between 1990 and 2013, the number of people suffering from anxiety, stress and depression increased by nearly $50 \%$, from 416 million to 615 million [3]. Close to $10 \%$ of the world's population is affected and mental disorders account for $30 \%$ of the global non-fatal disease burden [4]. While people of all ages and walks of lives are vulnerable to such afflictions, the status of medical students \& s is worthy of particular attention, since they at once belong to the high risk population due to their immense workload under a pressurized environment, and are at the forefront of the battle against mental illness in their capacity of future health care providers. In Bangladesh mental health is a least countable concern as in this country the number of population per physician is very high [5]. Medical education is regarded as highly intense and often overwhelming for the students all over the world [6]. A huge curriculum, limited course duration and difficult examinations constitute an environment of great mental pressure. Many of the students grow a sense of disappointment and inadequacy as they struggle to cope with demanding academic standards. In Bangladesh, there are an estimated 3.05 physicians per 10,000 populations [7]. Anxiety "is a psychologic and physiologic state characterized by cognitive, somatic, emotional, and behavioral components" [8]. Many research works so far have concluded that psychological problems start and/or exacerbate as the students begin medical schooling and remain poor throughout the whole training period [9]. These studies explain that medical $\mathrm{s}$ 
experiences a rising incidence of personal distress throughout their medical course, postgraduate training period, and later in physicians' professional life [9-11], and many of the times they may reach burnout level [12]. The fact that many studies reported high prevalence of stress related disorders among medical students and that burden of psychiatric disorders such as anxiety and depression among them is growing alarmingly may have long term implications [13]. At the same time, he/she develops a capability to form relevant interpersonal relationships, compassionate understanding, and to work in a team and in the community, which has significant importance in the medical field [14]. The prevalence of depression, anxiety and stress disorders among medical professionals and students have been found to be significantly higher than the rest of the populations in many studies [15-14]. However, very few of them were conducted in developing countries, particularly in Bangladesh. Since the etiology of these disorders are closely entwined with many socio-demographic, cultural and institutional factors; factors which vary greatly from country to country, it is essential to evaluate the status in each country to gain a more accurate, contextualized understanding. Generally, studies suggest that in comparison to the other professionals in the community, medical students and professionals, as well as the practicing physicians are exposed to higher academic and professional stress and therefore are prone to anxiety disorders that may compromise their physical, mental, and social health, subsequently affecting their professional success and excellence. The deterioration of mental health occurred throughout medical education starting from under graduation and it may continue later in postgraduate studies and professional life. Since better psychosocial health translates into greater productivity, well-being and capacity for adaptation and overcoming problems, like all other countries, developing nations like Bangladesh also must concentrate on how to nurture her future health professionals better; and to do that assessing the prevailing situation thoroughly is mandatory.

\section{OBJECTIVE \\ General Objective}

To identify the prevalence and factors associated with depression among medical students.

\section{Specific objectives}

To find out the relationship between educational factors with depression among the medical students

To determine the association of socio economic status with depression among the medical students

To find out the level of depression among the medical students

\section{METHOD}

This is an analytical cross-sectional study that was used to measure the prevalence of depression related factors among students in medical colleges in Dhaka. Study population consisted of medical students in medical college institutions at Dhaka, Bangladesh. Dhaka Medical College, Mugda Medical College, Delta Medical College and Holy Cross Medical College and Hospital were selected as the study sites. The sites were selected purposely depending on the fulfillment of the criteria that all these are located in Dhaka, provide medical education and training at different levels and are accessible to the researchers. The study was conducted from August 2019 to December 2019. Questionnaire was coded before entering the data to the computer by the researcher. The sample database was checked by double entry. SPSS version 22.0 was used for analyzing. The analysis part consisted of 2 parts, descriptive and analytical statistics. In analytic statistics, data was tested in bivariate and multivariate analysis. Odds ratio, chi-square test and multivariate logistic regression were used for beating association of different factors.

\section{Results}

A total of 360 research questionnaires were distributed among two medical college students of Dhaka and out of these participants, 310 participants completed the questionnaire and consent form. The response rate was $86.11 \%$ and subjects comprised 162 $(52.26 \%)$ male respondents and $148(47.74 \%)$ female respondents with a mean age of 21.4 years. While $33.87 \%$ students $(n=105)$ are $1^{\mathrm{St}}$ and $2^{\text {"d }}$ year students, $39.35 \%$ students $(n=122)$ students study in $3^{\text {nd }}$ and $4^{\text {th }}$ year, leaving $26.77 \%(n=83)$ students in the final year of their study. Among the respondents, 34.84\% ( $\mathrm{n}=108)$ students reside in hostels and $65.16 \%$ students $(n=202)$ reside in their own house. This study tries to figure out the association of depression with each individual factor while the others are adjusted. Table 4 shows the odds of female students developing depression is found to be 2.12(1/0.4741) times higher than their male counterparts when the other factors are adjusted (AOR $0.4741, \mathrm{p}$ value 0.0162 ). There is also a significant association between sleep and depression ( $p$ value $0.0460)$ which suggests that the odds of those sleeping $<8$ hours per day having depression is $1.82(110.5491)$ times higher than those sleeping for more than 8 hours per day. Other factors did not show any significant association after adjustment.

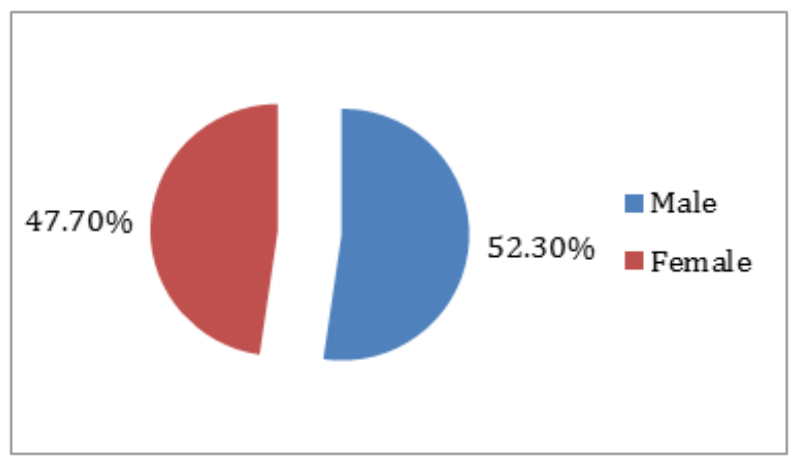

Fig-1: Sex of the respondents 


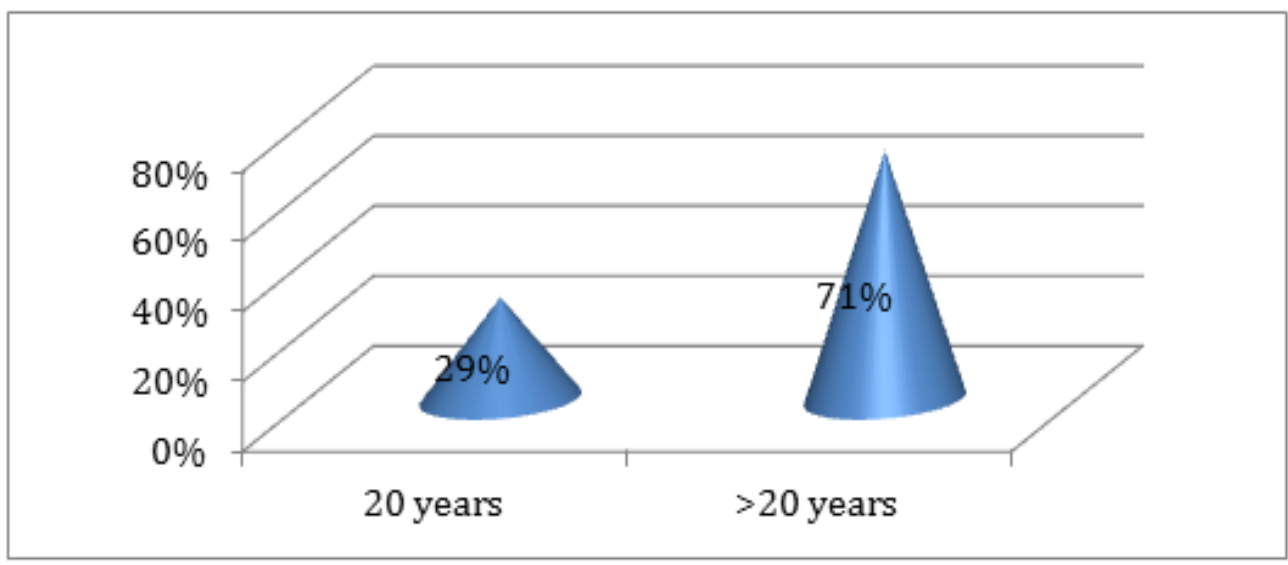

Fig-1: Age of the respondents

Table-1: Demographic characteristics of the study participants

\begin{tabular}{|l|l|l|l|}
\hline \multicolumn{2}{|l|}{ Demographic characteristics of the study participants (N= 310) } & Percentage \\
\hline Residence & Hostel/Mess & 108 & 34.8 \\
& Own house & 220 & 65.2 \\
\hline \multirow{5}{*}{ Academic year } & 1-2 year & 104 & 33.5 \\
& 3-4 year & 122 & 39.4 \\
& Final year & 84 & 27.1 \\
\hline \multirow{5}{*}{ Exercise } & Does not do exercise & 133 & 42.9 \\
\cline { 2 - 4 } & Sometimes & 133 & 42.9 \\
\cline { 2 - 4 } & Regularly & 44 & 14.2 \\
\hline \multirow{3}{*}{ Sleep } & 5_8hrs/day & 194 & 62.6 \\
\cline { 2 - 4 } & $>8$ hrs/day & 116 & 37.4 \\
\hline \multirow{2}{*}{ Smoking } & No & 250 & 80.6 \\
\cline { 2 - 4 } & Yes & 60 & 19.4 \\
\hline
\end{tabular}

Table-2: Distribution of depression according to gender

\begin{tabular}{|c|c|c|c|c|c|}
\hline \multirow[t]{2}{*}{ Gender $(n=310)$} & \multicolumn{5}{|c|}{ Depression } \\
\hline & \multicolumn{2}{|c|}{ Moderate } & \multicolumn{2}{|l|}{ Severe } & Total \\
\hline Female $0^{=} 148$ ) & $16.2 \%$ & (24) & $33.1 \%$ & (49) & $49.3 \%(73)$ \\
\hline Male $(n=162)$ & $22.8 \%$ & (37) & $14.2 \%$ & (23) & $37 \%(60)$ \\
\hline
\end{tabular}

Association of Depression with Socio-economic, Education and Lifestyle Factors

Table-a: Demographic factors

\begin{tabular}{|l|l|l|l|l|l|}
\hline Age: & Normal & Moderate & Severe & $\mathbf{X}^{\mathbf{L}}$ & p-value \\
\hline$<20$ years & $47(52.2 \%)$ & $21(23.3 \%)$ & $22(24.4 \%)$ & 1.470 & 0.479 \\
\hline$>20$ years & $130(59.1 \%)$ & $40(18.2 \%)$ & $50(22.7 \%)$ & 1.403 & 0.409 \\
\hline Sex & & & & & \\
\hline Male & $102(63 \%)$ & $37(22.8 \%)$ & $23\left(14.2 \% 5^{-}\right.$ & 15.678 & $<0.001$ \\
\hline Female & $75(50.7 \%)$ & $24(16.2 \%)$ & $49(33.1 \%)$ & 15.675 & $<0.001$ \\
\hline
\end{tabular}

Table-b: Education

\begin{tabular}{|l|l|l|l|l|l|}
\hline Academic Year & Normal & Moderate & Severe & $\mathbf{X}^{\mathbf{L}}$ & p-value \\
\hline $1 \& 2$ & $53(51 \%)$ & $25(24 \%)$ & $26(25 \%)$ & 8.321 & 0.080 \\
\hline $3 \& 4$ & $81(66.4 \%)$ & $20(16.4 \%)$ & $21(17.2 \%)$ & 8.321 & 0.081 \\
\hline 5 & $43(51.2 \%)$ & $16(19 \%)$ & $25(29.8 \%)$ & 8.322 & 0.080 \\
\hline
\end{tabular}


Table-c: Life style

\begin{tabular}{|l|l|l|l|l|l|}
\hline Exercise & Year & Normal & Moderate & Severe & $\mathbf{X}^{\mathrm{L}}$ \\
\hline No & $84(63.2 \%)$ & $12(9.0 \%)$ & $37(27.8)$ & 21.978 & $<.001$ \\
\hline Irregular & $64(48.1 \%)$ & $38(28.6 \%)$ & $31(23.3 \%)$ & 21.990 & $<.001$ \\
\hline $\begin{array}{l}\text { Regular } \\
\text { (ref.) }\end{array}$ & $29(65.9 \%)$ & $1125.0 \%)$ & $32(24 \%)$ & 21.983 & $<.001$ \\
\hline Residence & & & & \\
\hline Hostel & $56(51.9 \%)$ & $24(22.4 \%)$ & $28(25.9 \%)$ & 1.864 & 0.394 \\
\hline $\begin{array}{l}\text { Own Horne } \\
\text { (ref.) }\end{array}$ & $121(59.9 \%)$ & $37(18.3 \%)$ & $44(21.8 \%)$ & 1.884 & 0.404 \\
\hline Sleep & & & & \\
\hline 58hrs/day & $101(21.1 \%)$ & $44(22.7 \%)$ & $49(25.3)$ & 5.599 & 0.061 \\
\hline$>8$ hrs/Day & $76(65.5 \%)$ & $17(14.7)$ & $23(19.8 \%)$ & 5.588 & 0.062 \\
\hline Smoking & \multicolumn{5}{|l|}{} \\
\hline Yes & $35(58.3 \%)$ & $14(23.3 \%)$ & $11(18.3 \%)$ & 1.292 & 0.524 \\
\hline No (Ref.) & $142(56.8 \%)$ & $47(18.8)$ & $61(24.4 \%)$ & 1.292 & 0.520 \\
\hline
\end{tabular}

Table-4: Adjusted Analysis of Depression by the Multivariate Logistic Regression

\begin{tabular}{|l|l|l|l|l|l|l|}
\hline Profile & Reference & Estimate & OR & LCI, & UCL & F value. \\
\hline Academic year-3 ${ }^{\text {rd }}$ to 4th & 1 st/2nd & -0.462645 & 0.6296 & 0.3122 & 1,2639 & 0.1933 \\
\hline Academic year - 5th & 1 st/2nd & $-0.0{ }^{\prime} 77316$ & 0.9256 & 0.4459 & 1.9254 & 0.8354 \\
\hline BMI- & Normal & -0.058681 & 0.9430 & $0.517: 3$ & 1.7146 & 0.8474 \\
\hline Oven eight/Obese & 1 & 3 & 6 & 4 & 2 & 3 \\
\hline \multirow{2}{*}{ Gender - } & Female & -0.746313 & 0.4741 & 0.2554 & 0.8648 & 0.0162 \\
\cline { 2 - 7 } & Male & 0.740634 & 0.7457444 & 0.747644 & 0.737467 & 0.84738 \\
\hline Sleep - & $<8$ hrs/day & -0.599545 & 0.5491 & 0.3024 & 0,9849 & 0.0460 \\
\hline Smoking - & No & -0.407452 & 0.6653 & 0,2907 & 1.5017 & 0.3285 \\
\cline { 2 - 7 } & Yes & 0.67657 & 0.7747 & 0.7673457 & 0.767547 & 0.7747 \\
\hline Residence - & Hostel & -0.487928 & 0,6139 & 0.3356 & 1.1124 & 0,1094 \\
\hline Exercise - & Never & 0.386812 & 1.4722 & 0.8048 & 2.6993 & 0.2092 \\
\hline Exercise - & Never & -0.063618 & 0.9384 & $0.389: 3$ & 2.2091 & 0.8850 \\
\hline
\end{tabular}

\section{DISCUSSION}

Considering medical science has one of the toughest course curriculums, medical students should have suffered from psychological insults more than others. Hence it is logical to suspect that medical students at undergrad level may show a considerable level of depression, anxiety and stress [29]. In a densely populated developing country like Bangladesh where the whole medical system is overburdened, the students may face even more demanding situations. Also the socio-demographic, economic and other factors may vary between the public and private medical students, the latter being often neglected in the discourse of health in Bangladesh [30]. Therefore, this study aimed at investigating the prevalence of depression and its association with mental disorders among students of three private medical colleges in Dhaka. Bangladesh.

Psychological factors like depression have been assessed with the DASS 21 questionnaire to the respondents, this study shows that a significant proportion of medical students suffering from depression $42.9 \%$. Of those inflicted with such conditions, a high percentage suffers from the severe forms i.e. severe depression $54.1 \%$ and moderate depression $56.6 \%$. Other studies conducted in Indian sub-continent, countries with similar sociodemographic makeup, yielded comparable high numbers [31, 32].

Such a higher rate of prevalence of depression is to be expected considering the backdrop of prevailing socio-demographic, economic and institutional settings, as discussed before. Medical students also are in continuous fear of failing and fall apart from their course mates to 6 months minimum. The socio cultural practices of Bangladesh make them more and more vulnerable to suffer from these characters. Continuous pressure from family and relatives, social pressure and abusive reports from the journalists and politicians make life even harder for the medical students. Different socio demographic factors show important association with depression, anxiety and stress according to this study. Female students are found out to be more affected than their male counterparts, with $16.2 \%$ and $33.1 \%$ of females having moderate and severe depression respectively, compared to $22.8 \%$ and $14.2 \%$ of males. Adjust odds ratio shows that female students are 2.12 times more likely to suffer from depression than males. This is consistent with the other studies carried worldwide to see the association of depression [33-35]. This is also in line with women in the general population having a higher lifetime risk of 
depression [36]. Anxiety is also associated with female gender in the general population [37].

Our study also finds 2.99 times increased odds of females falling victim to anxiety than male students. This is supported by other studies among medical students. Female students are more prone to suffer from stress as well. There can be multiple explanation of this association of female sex, Hormones may play a significant role, whereas, natural health care seeking behavior, social status of female child, menstrual cycles, religious and cultural bindings all may have contribution in the causation.

\section{Conclusion and Recommendations}

The prevalence of depression is quite high among medical students at undergraduate level in Bangladesh. Different factors like sex, academic year, age, residence etc. have been proven to be independently associated with these psychological conditions at varying degree. These are valuable information if we are to devise a better, more supportive environment for the medical students. Particular attention should be paid towards the needs of the more vulnerable demographics: the female students and the students in 1" and 2" year. The factors identified in this study should prove to be a good starting point for further in depth exploration of casualties of mental illness among medical students through prospective researches in future. Prevalence of depression and illness should be determined among all medical students, including the public institutions. Similar studies with larger scopes encompassing more, preferably all medical colleges should be carried out. Medical students are frequently sufferers of depression. The reasons behind such high prevalence of psychological stressors should be extensively sought out through extensive studies. Other possible factors such as economic conditions should be explored in future to gain a better view of the bigger picture.

\section{REFERENCES}

1. Adams J. Straining to describe and tackle stress in medical students. Medical Education. 2004; 38(5):463-464.

2. Abnormal Psychology, By DL, Rosenhan and MEP. Seligman. (Pp. 730; illustrated; f17.95.) W. W. Norton: London. 2001. Psychological Medicine. 1985; 15(01):212

3. Roberts J. Junior doctors' years: training, not education. BMJ. 1991; 302(6770):225-228.

4. Dowling S. Emotional distress in junior doctors. BMJ. 1987; 295(6603):926-926.

5. Tyssen R, Vaglum P, GrOnvold N, Ekeberg. The relative importance of individual and organizational factors for the prevention of job stress during ship: a nationwide and prospective study. Medical Teacher. 2005; 27(8):726-731.
6. Willcock S, Daly NI, Tennant C. Burnout and Psychiatric morbidity in new medical graduates. Med J Malaysia. 2004; 1 81:357-60.

7. Tabassum Alvil FA MRa FAK. Depression, Anxiety and Their Associated Factors Among, journal of the college of physician and surgeons pakistan. 2010; 20(2). (122-126).

8. Ahmed I, Banu H, Al-Fageer R, Al-Suwaidi R. Cognitive emotions: Depression and anxiety in medical students and staff. Journal of Critical Care. 2009; 24(3): el-e7.

9. Yusoff M, Abdul Rahim A, Baba A, Ismail S, Mat Pa M, Esa A. Prevalence and associated factors of stress, anxiety and depression among prospective medical students. Asian Journal of Psychiatry. 2013; 6(2): 128-133.

10. Chandavarkar U, Azzam A, Mathews C. Anxiety symptoms and perceived performance in medical students. Depression and Anxiety. 2007; 24(2): 103-1 11.

11. Dyrbye L, Thomas NI, Shanafelt T. Systematic Review of Depression, Anxiety, and Other Indicators of Psychological Distress among U.S. and Canadian Medical Students. Academic Medicine. 2006; 81(4):354-373.

12. Smith C, Peterson D, Degenhardt Johnson J. Depression, anxiety, and perceived hassles among entering medical students. Psychology, Health \& Medicine. 2007;

13. Silver MX, Glicken AD. Medical student abuse. JAMA: The Journal of the American Medical Association. 1990; 263(4); 527.

14. Peterlini M, Tiberio I, Saadeh A. Pereira J, Martins M. Anxiety and depression in the first year of medical residency training. Medical Education. 2002; 36(1):66-72.

15. Aluoja A, Leinsalu M, Shlik J, Vasar V, Luuk K. Symptoms of depression in the Estonian population: prevalence, sociodemographic correlates and social adjustment. Journal of Affective Disorders. 2004; 78(1):27-35.

16. Eller T, Aluoja Vasar V, Veldi M. Symptoms of anxiety and depression in Estonian medical students with sleep problems. Depression and Anxiety. 2006; 23(4):250-256.

17. Blenkin H, Deary I, Sadler A, Agius R. Stress in NHS consultants. BMJ. 1995; 310(6978):534-534. 38. Ramirez A, Graham J, Richards M, Gregory W, Cull A. Mental health of hospital consultants: the effects of stress and satisfaction at work. The Lancet. 1996; ${ }^{3} 347(9003): 724-728$.

18. Kapur N, Borrill C, Stride C. Psychological morbidity and job satisfaction in hospital consultants and junior house officers: multicentre, cross sectional survey. BMJ. 1998; 317(7157):511512.

19. Frank E. Mortality rates and causes among U.S. physicians. American Journal of Preventive Medicine. 2000; 19(3): 155-159. 
Arifa Sultana; Sch J App Med Sci, Jan, 2021; 9(1): 54-59

20. Murray R. Alcoholism amongst Male Doctors in Scotland. The Lancet. 1976; 308(79881:729-731. Caplan R. Stress, anxiety, and depression in hospital consultants, general practitioners, and senior health service managers. BMJ. 1994; 309(6964): 1261-1263.

21. Firth-Cozens J. Emotional distress in junior house officers. BMJ. 1987; 295(6597):533-536.

22. Givens JTjia Depressed Medical Students Use of Mental Health Services and Barriers to Use. Academic Medicine. 2002; 77(9):918-921.

23. YusoffM, Abdul Rahim A, Baba A, Ismail S, Esa A. P-1408 - Prevalence and associated factors of stress, anxiety and depression among entering medical students. European Psychiatry. 2012; 27:1.

24. Weisman Nathanson C. Professional Satisfaction and Client Outcomes. Medical Care. 1985; 23(10):! 179-1192.

25. Haas J, Cook E, Puopolo A, Burstin H, Cleary P, Brennan T. Is the professional satisfaction of generalists associated with patient satisfaction? Journal of General al Medicine. 2000; 15(2): 122128 ,

26. Linn L. Health status, job satisfaction, job stress, and life satisfaction among academic and clinical faculty. JAMA: The Journal of the American Medical Association. 1985; 254(19):2775-2782.

27. Di Matteo M, Sherbourne C, Hays R. Ordway L, et al. Physicians characteristics influence patients' adherence to medical treatment: Results from the Medical Outcomes Study. Health Psychology. 1993; 12(2):93-102.

28. Iqbal S, Gupta S, Venkatarao E. Stress, anxiety \& depression among medical undergraduate students \& their socio-demographic correlates. The Indian journal of medical research. 2015 Mar; 141(3):354.

29. Singh A, Lai A and Singh S. Prevalence of depression among medical students of a private medical college in India. Online Journal of Health and Allied Sciences. 2011; 9(4).

30. Rizvi F, Qureshi A, Rajput AM, Afzal M. Prevalence of depression, anxiety and stress (by DASS scoring system) among medical students in Islamabad, Pakistan. Journal of Advances in Medicine and Medical Research. 2015 Apr 18:6975.

31. Kunwar D, Risal A, Koirala S. Study of depression, anxiety and stress among the medical students in two medical colleges of nepal. KathrnanduUniv Med J. 2016 Jan; 53(1):22-6.

32. Zoccolillo M, Murphy GE, Wetzel RD. Depression among medical students. Journal of affective disorders. 1986 Aug 31; 11(0:91-6.

33. Lloyd C, Gartrell NK. Psychiatric symptoms in medical students. Comprehensive psychiatry. 1984 Dec 31; 25(0:552-65.

34. Camp DL, Hollingsworth MA, Zaccaro DJ, Cariaga-Lo LD, Richards BF. Does a problembased learning curriculum affect depression in medical students? Academic Medicine. 1994 Oct 1; 69(10): S25-7.

35. Blazer DG, Kessler RC, McGonagle KA, Swartz MS. The prevalence and distribution of major depression in a national community sample: The National Comorbidity Survey. Am J Psychiatry. 1994; 151:979-86.

36. Regier DA, Farmer ME, Rae DS, Myers JK, Kramer MR, Robins LN, George LK, Karno M. Locke BZ. One-month prevalence of mental disorders in the United States and socio- demographic characteristics: The Epidemiologic Catchment Area study. Acta Psychiatric a Scandinavica. 1993 Jul 1; 88(1):3547. 